\title{
Teaching socio-environmental synthesis with the case studies approach
}

\author{
Cynthia A. Wei • William R. Burnside • Judy P. Che-Castaldo
}

Published online: 11 December 2014

(C) The Author(s) 2014. This article is published with open access at Springerlink.com

\begin{abstract}
Socio-environmental synthesis (S-E synthesis) is a research method and problem-solving approach that integrates existing knowledge and data from natural and social sciences to advance understanding of socio-environmental systems and to inform solutions to environmental problems. As science becomes more transdisciplinary and collaborative and as new opportunities presented by the information age change how we do science, the teaching of S-E synthesis is increasingly important for preparing future environmental problem solvers, scientists, and citizens. S-E synthesis also provides a rich context for classroom instruction that can facilitate the achievement of diverse learning objectives. Here, we discuss efforts to adapt the evidence-based teaching practice of the case study method for teaching about the complex and interdisciplinary approach of S-E synthesis. We provide insights about the effectiveness of this teaching approach and offer practical advice for writing and implementing S-E synthesis cases. These insights are informed by experiences creating and using S-E synthesis case studies, both ours and those of participants of a short course on "Teaching about SocioEnvironmental Synthesis with Case Studies" held at the National Socio-Environmental Synthesis Center (SESYNC). Assessment of S-E synthesis learning goals and the effectiveness of the case study method for teaching S-E synthesis are also discussed. Full development of this approach for teaching S-E synthesis will require a community effort, and our intention here is to offer a preliminary vision and qualitative assessment, to stimulate discussion, and to invite readers to join our efforts to create, use, and assess S-E synthesis case studies for teaching.
\end{abstract}

C. A. Wei $(\bowtie) \cdot$ W. R. Burnside · J. P. Che-Castaldo

National Socio-Environmental Synthesis Center (SESYNC),

1 Park Place Suite 300, Annapolis, MD 21401, USA

e-mail: cwei@sesync.org
Keywords Socio-environmental synthesis · Case study method · Case-based learning · Interdisciplinary education . Coupled human-natural systems $\cdot$ Pedagogy

\section{Introduction}

Given the urgency and complexity of current global environmental problems, conveying the importance of these issues to students without overwhelming them or engendering a sense of hopelessness is critical. One approach advocated by many educators (e.g., Kirk, n.d.) is to focus on how these problems can be solved and to empower students by helping them develop competencies needed to become productive citizens, environmental problem solvers, and scientists. The environmental studies and sciences community promotes this approach and, if the rise in popularity of environmental and sustainability courses and programs (Vincent et al. 2012) is any indication, the message is resonating with students. The challenge now is delivering on this promise.

Leaders of interdisciplinary environmental and sustainability (IES) programs have identified two critical elements for preparing students to address complex environmental problems. First is a focus on the human-nature interface and systems thinking (Vincent and Focht 2011; Vincent et al. 2012). Nearly all environmental issues involve human social systems and the ecosystems in which they are embedded. These socio-environmental systems are also called "coupled human and natural systems" in recognition of the tight, intrinsic links among the human and broader natural components (see Liu et al., 2007). Second, IES leaders consider interdisciplinary, problem-solving approaches that engage both natural and social sciences as an essential part of environmental education (Vincent and Focht 2011). Socio-environmental synthesis (S-E synthesis) is one such approach that integrates existing knowledge, data, and methodologies from the natural 
and social sciences to understand and inform solutions to environmental problems.

Because of its emphasis on coupled human-natural systems and on integrating knowledge across disciplines, teaching S-E synthesis may be an effective way of helping students develop the competencies IES leaders value. Currently, US environmental programs are not adequately training students in interdisciplinary problem solving (Clark et al. 2011). Issues include insufficient guidance on how students can truly integrate and apply knowledge to real-world problems and a difficulty moving from multidisciplinarity into the interdisciplinarity and transciplinarity ${ }^{1}$ required to understand and address socio-environmental problems. Such a move involves a shift from the combination of independent disciplinary perspectives to the holistic integration of knowledge, data, and insights from disciplines and user communities. S-E synthesis is a promising approach for providing such guidance because it emphasizes integrating interdisciplinary or transdisciplinary knowledge and using it to address real environmental problems. Teaching S-E synthesis can also provide students with a context to practice interdisciplinary problem-solving skills.

One promising approach for teaching S-E synthesis builds on the case study method, ${ }^{2}$ an active-learning pedagogy. The case study method is well developed and used in many fields, including business, law, medicine, and more recently, science. Case study teaching in science is supported by several national organizations, most notably the National Center for Case Study Teaching in Science (NCCSTS), which provides training and resources about developing and using case studies (e.g., Herreid 1994, 1997) and a peer-reviewed collection of science case studies. There is also increasing evidence for the effectiveness of case studies in enhancing important skills such as critical thinking and conceptual understandings (e.g., Herreid 2005; White et al. 2009; Lundeberg et al. 2011). We propose that the case study method may also be particularly effective for teaching about $\mathrm{S}$-E synthesis and related concepts and competencies. However, given the complexity and interdisciplinary nature of socio-environmental synthesis, existing best practices for creating and teaching with case studies will

\footnotetext{
${ }^{1}$ Transdisciplinarity is distinguished from interdisciplinarity by its emphasis on the integrative co-development of conceptual frameworks and novel methodologies across disciplinary perspectives (Miller et al. 2008). Transdisciplinary research is further distinguished by some based on its inclusion of diverse forms of knowledge and its relative breadth of professional collaboration, which often include non-academics and stakeholders (Mobjörk 2010).

${ }^{2}$ As a point of clarification, our focus on case studies involves their use in teaching rather than as a qualitative research method commonly used in social science (Baxter and Jack 2008). Cases for the classroom may not follow the standards of cases used in research (Baxter and Jack 2008) and further differ by including teaching notes that provide background information, learning goals and objectives, guidance on classroom management, suggested assessment questions, and supplementary materials. In other words, a case study teaching activity contains everything that another instructor would need to teach the case.
}

need to be modified or newly developed for teaching about $\mathrm{S}$ E synthesis.

Our goal in this paper is to engage readers in our efforts to advance the teaching of socio-environmental synthesis and to adapt the case study method to do so. Our discussion is informed by experiences developing and implementing S-E synthesis cases and a short course, "Teaching about SocioEnvironmental Synthesis with Case Studies," held at the National Socio-Environmental Synthesis Center (SESYNC) in the summers of 2013 and 2014. Our discussion draws upon experiences of the diverse group of course participants, including faculty, postdocs, graduate students, and others. We hope readers will join us in our efforts to create, use, and assess S-E synthesis case studies for teaching.

\section{Teaching socio-environmental synthesis: defining core concepts and competencies}

Because of the interdisciplinary nature of socio-environmental problems, the practice of S-E synthesis involves a broad range of natural science and social science disciplines. The competencies related to $\mathrm{S}-\mathrm{E}$ synthesis are also diverse, including cognitive skills like systems thinking and general skills like facilitating teamwork. Many competencies are not unique to S-E synthesis, which may rely on different competencies depending on the problem at hand. Given the breadth of what S-E synthesis encompasses, understanding what it means to teach $\mathrm{S}-\mathrm{E}$ synthesis and defining learning goals for associated courses or activities can be challenging.

For clarity, we define four broad learning goals that are integral to the S-E synthesis approach and that serve to organize related concepts and competencies (Table 1). Many of the concepts and competencies important for learning about S-E synthesis fall within these four broad categories. For example, Berkowitz et al. (2013) have identified seven capacities ${ }^{3}$ for $\mathrm{S}$ E synthesis proficiency, each of which relate to one of the four broad learning goals we have defined.

The first two learning goals involve understanding the processes inherent in socio-environmental issues and focus on developing conceptual foundations. A systems perspective (goal 1) is necessary because interactions among the components of an S-E system can cause the system as a whole to behave in ways that cannot be predicted by studying the parts in isolation. Furthermore, interactions within and between components and sub-systems often occur across different scales (goal 2) and thus have important implications for understanding the behavior of a system and for making

\footnotetext{
${ }^{3}$ The seven capacities include (1) synthesis inquiry and critique competencies, (2) epistemological and collaborative competencies, (3) critical and creative thinking competencies, (4) dynamic systems thinking competency, (5) communication competency, (6) normative literacy, and (7) actionable science literacy.
} 
Table 1 Four broad conceptual and competency-based learning goals that are integral to the S-E synthesis approach

\begin{tabular}{ll}
\hline $\begin{array}{l}\text { S-E synthesis } \\
\text { learning goals }\end{array}$ & Students should develop \\
\hline $\begin{array}{l}\text { Goal 1 (concept) } \\
\text { Goal 2 (concept) }\end{array}$ & $\begin{array}{c}\text { An understanding of socio-environmental systems } \\
\text { An understanding of how patterns and processes } \\
\text { are scale and context dependent }\end{array}$ \\
$\begin{array}{c}\text { Goal } 3 \\
\text { (competency) } \\
\text { data, knowlity to find, analyze, and synthesize existing }\end{array}$ \\
$\begin{array}{c}\text { Goal } 4 \\
\text { (competency) }\end{array}$ & $\begin{array}{c}\text { interdisciplinary or transdisciplinary teams } \\
\text { intity to co-develop research questions in }\end{array}$ \\
\hline
\end{tabular}

management decisions. For example, the biological processes of long-lived organisms like redwood trees or elephants span several decades and require long-term policies to effectively manage them (Cumming et al. 2006). However, the social institutions and policies that manage them often operate on much shorter time scales and thus are often ineffective.

Data fluency (goal 3) and the ability to co-develop research questions (goal 4) focus on the problem-solving and interdisciplinary competencies that are essential to S-E synthesis and emphasized by environmental programs. The ability to find, analyze, and synthesize existing data, knowledge, methods, and ideas (goal 3) are competencies needed to perform synthesis as a research method (Carpenter et al. 2009) and includes being able to manage and visualize data and to create simulations and other models. Synthesis also involves the integration of ideas, methods, and knowledge across domains, a cognitive competency identified by environmental education leaders as a key skill for interdisciplinary environmental education (Vincent and Focht 2011). Moreover, synthesis and integrative learning have been identified by the American Association of Colleges and Universities as Essential Learning Outcomes needed to prepare students for the profound challenges of our time (AAC\&U, n.d.). The interdisciplinary, epistemological, communications, and teamwork competencies associated with goal 4 are part of the 21 st century skills recently promoted in higher education (AAC\&U, 2010, Pellegrino and Hilton 2010) and are necessary for working collaboratively across disciplines, engaging with professionals outside of traditional disciplines, and producing science that translates into action (Palmer 2012).

Although synthesis research is common in many disciplines (e.g., Cooper 2009; Rodrigo et al. 2013) and approaches to synthesis research and teaching have been defined in some fields (Cooper 2009; Kemp and Boynton 2011), socio-environmental synthesis involves challenges unique to synthesis across the natural and social sciences, domains that differ in many ways. While the definitions, methods, and frameworks for synthesis from other disciplines will be helpful in understanding S-E synthesis (Kemp and Boynton 2011), we need to study the examples of synthesis in the socio- environmental domain to fully understand this still-evolving process. Similarly, effective teaching and learning of S-E synthesis will require clear, compelling examples of S-E synthesis.

\section{Adapting the case study method for teaching S-E synthesis}

Compelling stories are at the heart of the case study method (Herreid 1994, 2005). Often presented as a problem or scenario with characters and dialog, these stories provide context to abstract ideas and concepts and offer a more tangible means for students to understand the relevance of the lessons at hand. They also engage students by personalizing the problem or issue and making it accessible. Given the complex nature of socio-environmental problems, these features of the case study method make it particularly appealing for teaching S-E synthesis. However, the full promise of this teaching approach stems from the powerful combination of engaging examples with student-centered teaching. Mounting evidence suggests that the traditional lecture-only mode of teaching is relatively ineffective for teaching skills that are particularly important for S-E synthesis, such as critical thinking, teamwork, and problem solving, and are ineffective for helping students remember concepts in the long term (Handelsman et al. 2004; DeHaan 2005; Wieman 2007; Freeman et al. 2014). In response, there is a growing emphasis on the use of studentcentered, evidence-based teaching methods such as Peer-Led Team Learning (PLTL) (Gafney and Varma-Nelson 2008), inquiry-based learning (Ebert-May et al. 1997), problembased learning (PBL) (Allen and Tanner 2003), and the case study method (Herreid 1997). These student-centered approaches shift the focus of teaching away from the instructor as a source of knowledge towards the student as an active participant in his or her own learning (AAAS 2011).

Given the broad range of courses in which socioenvironmental synthesis may be introduced, an additional feature of the case study method that is particularly attractive for teaching about S-E synthesis is its flexibility. There are several methods for teaching and creating cases: each has unique advantages but all use flexible structures that should allow cases to be modified for different courses. As a pedagogy first used in teaching students of business, law, and medicine, the case study method is fundamentally about analyzing problems and issues (Killen 2007), and the approach has been adapted to the types of problems and issues in each field. More recently, the approach has been adapted for the teaching of science and is now well-established in that arena (Herreid 2005). We expect that the case study method can be readily adapted for teaching S-E synthesis as well.

Adapting the case study method will require careful consideration of how case studies can be implemented for teaching S-E synthesis and how effective they are in helping 
students to achieve associated learning goals. We began this inquiry by developing two exemplar S-E synthesis case studies, one of which has since been tested in multiple settings. Based on our experience developing and using these cases and the experiences of several participants in the Teaching SocioEnvironmental Synthesis with Case Studies short course, we provide preliminary evidence for the effectiveness of this approach and share practical insights for developing and teaching S-E synthesis cases.

\section{A tale of two case studies: insights for creating S-E synthesis cases}

The first challenge we faced when developing our S-E synthesis cases was choosing a well-suited problem or topic. To facilitate this process for ourselves and others, we developed guidelines for what we consider to be important elements of an S-E synthesis case for teaching: cases should (1) focus on a socio-environmental problem or issue, (2) include specific learning objectives based on one or more of the S-E synthesis learning goals described earlier, (3) illustrate the coupled nature of socio-environmental systems, and (4) challenge students to synthesize natural and social science data and/or knowledge.

For our first case study, Save the Turtles! And the Grizzlies? Or the Woodpeckers? Prioritizing Endangered Species Conservation, we focused on conservation and recovery planning for US endangered species, the subject of coauthor Judy Che-Castaldo's research. This case challenges students to make decisions about conservation priorities for five threatened and endangered species by synthesizing four different types of information: biological characteristics, economic considerations, sociocultural values, and threat factors. In the activity, students form mock management teams and work in small groups to prioritize the species for management efforts, initially based on each factor alone and ultimately based on a synthesis of all factors together. Students are challenged with a seemingly simple ranking task according to conservation priorities, but this task challenges them to consider how different types of data can be synthesized and thus focuses on goal 3.

Our second case demonstrates the coupled nature of socioenvironmental systems. We found an excellent example with the traditional Balinese wet rice cultivation system, which beautifully illustrates the interconnected dynamics of the system's components. Pest populations, hydrological cycles and water availability, and harvest and planting schedules determined by water temple priests interact to affect rice productivity in surprising ways. Based on the work of anthropologist Stephen Lansing and ecologist James Kremer (Lansing and Kramer 1993), this case provides a compelling example of how results from S-E synthesis can inform policy decisions.
For this case, which we titled The Blind Spot in the Green Revolution: Temples, Terraces and Rice Farmers of Bali, we used the interrupted case method, in which students are given information in a stepwise fashion and are challenged at each step to analyze and discuss the information provided.

In writing these cases, we discovered how difficult it is to develop a case that can teach all the essential learning goals of S-E synthesis and how easy it is for a case to rapidly expand in length and complexity. Our goal was to make simple and short S-E synthesis cases that could be used over one or two class periods, as this makes the exercise easier to fit into course schedules and for others to implement. However, both cases ended up longer than we intended despite our efforts to keep them simple. Likewise, many participants of the short course faced the same difficulty. Because of the interdisciplinary nature of S-E synthesis and the inherent complexity of S-E systems, it is a challenge to keep from expanding the scope and length of an S-E synthesis case to adequately address its many relevant aspects. One way to manage this tradeoff is to focus on one or two key learning goals rather than attempting to address all relevant S-E synthesis learning goals in a single case. For example, the Endangered Species case focuses on highlighting the importance of and challenges in integrating data from the natural and social sciences, whereas the Bali case focuses on highlighting the coupled structure and system dynamics inherent in traditional Bali rice cultivation. Another strategy, which we used for both cases, is to create a simple "base case" that addresses the core principles of the case and then to add depth and detail by suggesting modifications for advanced explorations. This approach also allows instructors to modify cases to better fit the level and content of their courses.

Through this process of creating new cases, we found that being familiar with the focal issue greatly facilitates the process of creating and defining the scope of the case. Because endangered species recovery is the subject of research for one of us, we knew what resources were available, how to access them, and their potential limitations. This familiarity helped us identify an activity that would be both relevant and feasible.

\section{S-E synthesis cases in the classroom: insights on what works}

The most critical insights for developing a case study approach for teaching about socio-environmental synthesis have come from testing S-E synthesis cases in the classroom. We have used the Endangered Species case study in multiple contexts: twice with two cohorts of SESYNC undergraduate interns, and twice in abbreviated form with the short course participants. Additionally, other instructors have used the case in a graduate-level marine conservation biology field course and an upper level environmental science course. We also conducted phone interviews with four short-course 
participants to collect insights from testing their own S-E synthesis case studies. These four cases included Minnesota Wolf Hunt, Do Good Seawalls Make Bad Neighbors?, Western Alaska Salmon Revolt, and Ecosystems, Economics, and Equity in the Floodplain. ${ }^{4}$ Our collective experiences confirmed some of the reported benefits of using the case study method and supported our hypothesis that it is particularly effective for teaching about S-E synthesis. Testing these cases provided four primary insights about the usefulness of case studies for teaching about socio-environmental synthesis.

First, we confirmed that cases successfully engage students. Several instructors found that the cases engaged students to a greater degree than lectures on the same topic. In the Minnesota Wolf Hunt and the Western Salmon Revolt, the authors noted that the local relevance of these issues stimulated a great deal of curiosity and interest and kept students engaged in the exercises. The Minnesota Wolf Hunt case, which began with students reading a recent news story from the local paper, was relatable, relevant, and real. The case was so successful at motivating students to learn and discuss the wolf hunt controversy that several reported continued discussions outside the class with their families and friends.

Second, the structure and format of the activities are critical for engaging students' intellectual curiosity and sustaining their interest. For example, we found in the Endangered Species case that the format of the exercise, where students were challenged to make prioritization decisions by combining different data sets, was very effective in engaging students and stimulating thoughtful discussion. This was true across audiences, including the undergraduate interns, graduate students, and short-course participants (predominantly faculty). The challenge presented by the prioritization activity prompted discussions about important issues for S-E synthesis such as the difficulty of making decisions with incomplete data, the challenges of integrating qualitative and quantitative data, and the understanding of how scientific data can inform policy. The format of this case was modified for the Good Seawalls case; students were asked to decide between five options for dealing with shoreline erosion based on five criteria: economic, environmental, hazards, legal, and sociocultural. Again, students gave positive feedback, noting that the exercise was engaging, and highlighted the importance of integrating natural and social science perspectives. The opportunity to wrestle with a problem and the chance to work in teams on a problem provided by this type of case contributed to student engagement and, ultimately, student learning.

Other formats, such as small group and role playing, also worked particularly well for certain types of cases. The smallgroup format, where students work in groups of three to four, works particularly well for teaching the interdisciplinary and

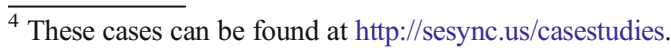

collaborative skills critical for S-E synthesis. In the Endangered Species case, students noted that one of the most valuable lessons from the exercise was discovering the differing perspectives that their peers had on the issue at hand. Because our interns come from diverse undergraduate majors and backgrounds, the diversity of perspectives created opportunities for students to experience and navigate interdisciplinary discourse. Generally, student diversity contributed to an activity's success.

The role-playing format can also be very effective in engaging students. In the Floodplains case, students explored different stakeholder perspectives on floodplain management options through role-play. This challenged them to understand and negotiate with multiple, often conflicting perspectives, which is a critical skill for transdisciplinary work. One author of this case cautioned that class size and activity timing are critical to the success of the role-play technique. Too few students or a lack of comfort among students may impede successful implementation of role-play. Another S-E synthesis case author also pointed out that role-play may be difficult if roles are easily stereotyped or if students do not have enough information or understanding of a particular perspective.

Our experiences also revealed that the case study method, which is often open ended and less predictable than traditional teaching methods, enables students to arrive at their own insights and to discover lessons that were not explicitly planned. For example, in the Endangered Species case, our students were frustrated by the gaps in the data provided. But one intern astutely observed that, in practice, managers are usually forced to make decisions without complete information. She concluded that she just had to do the best she could with what she had and that our exercise was a good reflection of real-world challenges.

Finally, our experiences with S-E synthesis cases confirmed that the case study approach is particularly effective for teaching about socio-environmental synthesis because it provides clear examples to illustrate complicated, multidimensional concepts and problems. Cases provide opportunities for students to apply the abstract concepts and theories of S-E synthesis to actual examples and problems. As Minnesota Wolf Hunt co-author, Dr. Teresa Shume, noted, "Environmental problems are inherently complex, and students need a broader set of perspectives [i.e. systems perspectives]. A case study gives you a tangible, manageable example that students can hang onto without being overwhelmed... SE synthesis cases permit you to see the complexity yet does so within a manageable scope."

\section{S-E synthesis cases in the classroom: lessons learned}

As with any teaching activity, the effectiveness of a case depends upon how well it is implemented in the classroom. 
But successful implementation depends on teaching skills and experience. Our experiences teaching with the Endangered Species case were critical for understanding how to implement it and provided insights on changes needed for using it in different contexts. Our use of small groups and the diversity of majors among the students enhanced the quality of their discussions. However, our interns were predominantly upperclassmen, and the structure of the case may not work as well in more homogenous classes or with younger students. One possible adaptation is to interrupt small group conversations with facilitated large group discussions to ensure that the discussions address the learning goals.

Our collective experiences testing cases also emphasized that time management can only realistically be determined after the case has been tried in a classroom; we greatly underestimated the time that should be allotted for different parts of our case. Time estimates are critical for classroom planning, and thus, important features of case study teaching notes are updated time estimates, suggested shortcuts, and ways to shorten or lengthen the case depending on the time available.

While such practical guidance is important, our experience also raised the question: is S-E synthesis too complex to teach via stand-alone case studies, which typically target a small set of competencies and easily defined concepts? Students cannot be expected to master $\mathrm{S}-\mathrm{E}$ synthesis via a single case. However, cases are usually embedded within a broader context, and this is particularly important to consider for S-E synthesis. We propose a few strategies to address this challenge. First, cases may be embedded within a larger course unit in which associated concepts are introduced through earlier lessons. Alternatively, concepts might be introduced across a series of related cases. However, both of these approaches - embedding a case within a larger unit and presenting a series of smaller cases - still require a substantial amount of overall course time devoted to teaching S-E synthesis and may be appropriate only for certain courses. The latter approach was adopted by a SESYNC-funded group studying the teaching of S-E synthesis via multi-week case study modules (Berkowitz et al. 2013). These modules follow the jigsaw style of case studies, in which students are assigned to research different aspects of a topic and then use their newfound expertise to help solve a broader problem in collaboration with teammate "experts" in complementary fields or methods (Herreid 2005).

A key effort in the development of a case study approach for teaching about S-E synthesis will be the continued collection and sharing of such insights as more S-E synthesis cases are tested. We encourage authors to revise their S-E synthesis cases, which we publish on our website (www.sesync.org), in response to classroom testing. As more S-E synthesis case are tested, we will use the resulting insights to shape and develop more-refined guidelines and best practices for teaching S-E synthesis with case studies. We also invite the community to test the S-E synthesis cases in our collection and provide helpful feedback on issues such as classroom management. ${ }^{5}$

\section{Assessing the effectiveness of S-E synthesis case studies}

Thus far, we have developed guidelines for creating S-E synthesis case studies, fostered the creation of a growing collection of S-E synthesis cases, and gathered formative assessments ${ }^{6}$ about the implementation of these cases. However, full development of the case study approach for teaching about S-E synthesis will require further assessment of S-E synthesis cases. First, continued formative assessments will be gathered to help hone the implementation of individual cases and develop best practices for all S-E synthesis cases. Second, summative assessments of tested cases are needed to understand their effectiveness in teaching students about S-E synthesis and related concepts and competencies and to understand why the case study approach works for teaching S-E synthesis.

Determining whether S-E synthesis case studies effectively teach students about S-E synthesis will involve assessment of student learning gains relative to case-specific learning goals. Currently, we have some evidence of positive student learning gains for S-E synthesis learning goals from trials of individual cases where post-exercise assessments were done (e.g., Endangered Species, Wolf Hunt, and Good Seawalls cases). One learning goal for the Endangered Species case was that students should be able to explain the importance of considering interdisciplinary sources of data. Responses received from both cohorts of interns (18/26 total) on a post-exercise survey indicated positive learning gains for the majority of students.

However, drawing general conclusions at this point from the assessments of individual cases is challenging for several reasons. First, because these cases are relatively new, opportunities to test them have not been extensive. As more cases are tested, we will continue to collect insights from instructors to better understand how to effectively create and implement $\mathrm{S}-\mathrm{E}$ synthesis cases and to better evaluate the effectiveness of the case study method for teaching S-E synthesis. Second, the assessment strategies employed so far have varied widely, making comparison difficult; some instructors used a survey following the case study exercise, as we did, while others informally assessed student learning gains through personal interactions during the case. Third, definitions and criteria for assessing student learning vary among cases, particularly for

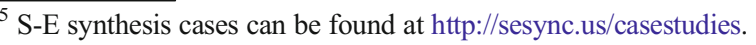

${ }^{6}$ Formative assessments provide feedback and insights to improve the process or project being assessed, while summative assessments judge the effectiveness of a process or project at completion.
} 
competency-based learning goals. The notion of what constitutes competency is often difficult to define and even harder to measure. For example, the ability to work in interdisciplinary teams involves a multi-faceted suite of skills and concepts, and interdisciplinary work itself is a complicated concept with varying definitions (Boix-Mansilla 2005).

To address these challenges, we need to compare learning outcomes of cases using common assessment metrics and tools. Fortunately, there are existing assessment tools and approaches for process skills and competencies that we can use for assessing S-E synthesis cases. For example, the AAC\&U Values Rubric provides guidance on how to assess such competencies as "critical thinking," "integrative learning," or "teamwork" (AAC\&U 2010). For assessment of interdisciplinary writing, Veronica Boix-Mansilla and colleagues have developed an empirically-tested rubric (BoixMansilla et al. 2009). Our efforts going forward will include engaging S-E synthesis case study authors and users to use these assessment metrics and tools and to help identify and develop new ones as needed.

\section{Conclusion}

As the Earth's population heads upward of 7 billion, the globalization of people, money, and information is creating connections among societies and ecosystems at an unprecedented pace and scale. Understanding these connections and their implications is daunting, but socio-environmental synthesis is a powerful approach for addressing this challenge. The explicit focus on transdisciplinary integration and systems thinking makes teaching about socio-environmental synthesis a priority for environmental education and a much needed complement to traditional approaches. In turn, case studies are an excellent way of making S-E synthesis and the complexity of S-E systems tangible, accessible, and engaging.

To meet the learning goals for teaching S-E synthesis and to train students in the competencies that environmental leaders value (e.g., interdisciplinary problem solving, synthesis, and systems thinking), it is clear that a single case, or even a single course, will not be sufficient. In addition, course time to address S-E synthesis is often limited, particularly in courses that are not focused on interdisciplinary environmental topics. We contend that there is still great value in introducing the concept of socioenvironmental synthesis through single, stand-alone cases. Teaching S-E synthesis for the purpose of training future researchers and problem solvers is critical, but it is not the exclusive goal of environmental education. Many environmental education programs, as well as many institutions as a whole, emphasize the importance of developing environmental literacy and preparing students to be environmental citizens (Advisory Committee for Environmental Research and Education 2009). An awareness of S-E synthesis should be part of this goal.
Additionally, embedding S-E synthesis cases within different courses across disciplines will likely lead students to appreciate its broad relevance and importance. This is especially critical considering that undergraduates may take many career paths that we cannot predict at the time we teach them; some of our students may decide later in their careers to enter an environmental field or profession, while others may become the policy makers, leaders, and decision makers we seek to engage in transdisciplinary, S-E synthesis research. Many of the S-E synthesis cases developed by our short course participants can be used in disciplinary-based courses such as chemistry, engineering, biology, ecology, anthropology, and public health, as well as skills-focused courses in GIS and remote sensing. For these courses, S-E synthesis cases are vehicles to engage students and to provide relevance and context for disciplinary content. S-E synthesis cases could also fit well into courses in other disciplines already familiar with casebased teaching methods, such as sustainable business and environmental law.

As we continue to develop the case study approach for teaching about S-E synthesis, our efforts will be informed by the continuing dialog in the community about the knowledge and skills needed to carry out S-E synthesis and effective ways to teach associated concepts and competencies. Much remains to be done, and progress will require a community effort. Our intention here is to stimulate discussion, and we invite you to join our efforts to create, use, and assess S-E synthesis case studies for teaching.

Acknowledgments We would like to thank the participants of the 2013 and 2014 SESYNC short course on Teaching about Socio-Environmental Synthesis with the Case Study Method and the 2013 and 2014 SESYNC summer interns for their feedback and insights on our case studies. We are also immensely grateful to Dr. Clyde Herreid for sharing his expertise and knowledge of the case study method as a short course instructor. Case study authors Dr. Sandra Cooke, Dr. Megan McPhee, Dr. Stephen Scyphers, and Dr. Theresa Shume shared their valuable experiences and insights from testing their cases, and Dr. Bretton Alvare, Dr. David Hawthorne, Dr. Margaret Palmer, and Dr. Jonathan Kramer contributed to and provided support for the development of the cases and short course. The authors are also grateful to Dr. J. Stephen Lansing for his inspiration and encouragement in developing the case study based on his work. This work was supported by the National Socio-Environmental Synthesis Center (SESYNC) under funding received from the National Science Foundation DBI-1052875.

Open Access This article is distributed under the terms of the Creative Commons Attribution License which permits any use, distribution, and reproduction in any medium, provided the original author(s) and the source are credited.

\section{References}

AAAS (2011) Vision and change in indergraduate biology education final report. In: Brewer C, Smith D (eds) American Association for the Advancement of Science, Washington DC, p 100 
AAC\&U (n.d.) Liberal education and America's promise: essential learning outcomes. http://www.aacu.org/leap/vision.cfm Accessed Sept 26,2013

AAC\&U (2010) Value Rubrics. https://www.aacu.org/value/rubrics. Accessed Oct. 15, 2014

Advisory Committee for Environmental Research and Education (2009) Transitions and tipping points in complex environmental systems

Allen D, Tanner K (2003) Approaches to cell biology teaching: learning content in context - problem-based learning. Cell Biol Educ 2:7381. doi:10.1187/cbe.03-04-0019

Baxter P, Jack S (2008) Qualitative case study methodology: study design and implementation for novice researchers. 13:544-559

Berkowitz A, Alvare B, Grant B, et al. (2013) The SESYNC SocioEnvironmental Synthesis Teaching Study: defining, measuring, and fostering student learning. Ecol. Soc. Am. Poster Presentation?

Boix-Mansilla V (2005) Assessing student work at disciplinary crossroads. Chang Mag High Learn 37:14-21. doi:10.3200/CHNG. 37.1.14-21

Boix-Mansilla V, Duraisingh ED, Wolfe CR, Haynes C (2009) Targeted assessment rubric: an empirically grounded rubric for interdisciplinary writing. J High Educ 80:334-353. doi: 10.1353/jhe. 0.0044

Carpenter SR, Armbrust EV, Arzberger PW et al (2009) Accelerate synthesis in ecology and environmental sciences. Bioscience 59: 699-701. doi:10.1525/bio.2009.59.8.11

Clark SG, Rutherford MB, Auer MR et al (2011) College and university environmental programs as a policy problem (part 2): strategies for improvement. Environ Manag 47:716-26. doi:10.1007/s00267-0119635-2

Cooper H (Duke U (2009)) Research synthesis and meta-analysis: a step by step approach (applied social research methods), Fourth. 1-280

Cumming GS, Cumming DHM, Redman CL (2006) Scale mismatches in social-ecological systems: causes, consequences, and solutions. 11

DeHaan RL (2005) The impending revolution in undergraduate science education. J Sci Educ Technol 14:253-269. doi:10.1007/s10956005-4425-3

Ebert-May D, Brewer C, Allred S (1997) Innovation large active. Bioscience 47:601-607

Freeman S, Eddy SL, McDonough M, et al. (2014) Active learning increases student performance in science, engineering, and mathematics. Proc Natl Acad Sci 1-6. doi: 10.1073/pnas.1319030111

Gafney L, Varma-Nelson P (2008) Peer-led team learning. 1-156

Handelsman J, Ebert-may D, Beichner R, et al. (2004) Scientific teaching. Science (80) 304:521-522
Herreid CF (1994) Case studies in science - a novel method of science education. J Coll Teach Sci 221-229

Herreid CF (1997) What is a case? J Coll Teach Sci 27:92-94

Herreid CF (2005) Using case studies to teach science. In: Action Biosci. $\mathrm{http} / / /$ actionbioscience.org/education/herreid.html. Accessed $26 \mathrm{Sep}$ 2013

Kemp WM, Boynton WR (2011) Synthesis in estuarine and coastal ecological research: what is it, why is it important, and how do we teach it? Estuar Coasts 35:1-22. doi:10.1007/s12237-011-9464-9

Killen R (2007) Using case study as a teaching strategy. Teach. Strateg. Outcomes-based Educ., Second. Juta and Company, Ltd., Capet Town, South Africa, pp 295-307

Lansing SJ, Kremer JN (1993) Emergent properties of Balinese water temple networks: Coadaptation on a rugged fitness landscape. American Anthropologist. 95 (1): 97-114

Liu J, Dietz T, Carpenter SR et al (2007) Complexity of coupled human and natural systems. Science 317:1513-6. doi:10.1126/science. 1144004

Lundeberg M, Kang H, Wolter B et al (2011) Context matters: increasing understanding with interactive clicker case studies. Educ Technol Res Dev 59:645-671. doi:10.1007/s11423-010-9182-1

Miller TR, Baird TD, Littlefield CM, Kofinas G (2008) Epistemological pluralism: reorganizing interdisciplinary research. 13

Mobjörk M (2010) Consulting versus participatory transdisciplinarity: a refined classification of transdisciplinary research. Futures 42:866873. doi:10.1016/j.futures.2010.03.003

Palmer M (2012) Socioenvironmental sustainability and actionable science. Bioscience 62:5-6. doi:10.1525/bio.2012.62.1.2

Pellegrino JW, Hilton ML (2010) Learning DD education for life and work: transferable knowledge and skills in the $21 \mathrm{st}$ century. $1-4$

Rodrigo A, Alberts S, Cranston K et al (2013) Science incubators: synthesis centers and their role in the research ecosystem. PLoS Biol 11:e1001468. doi:10.1371/journal.pbio. 1001468

Vincent S, Focht W (2011) Interdisciplinary environmental education: elements of field identity and curriculum design. J Environ Stud Sci 1:14-35. doi:10.1007/s13412-011-0007-2

Vincent S, Bunn S, Stevens S (2012) Results from the 2012 census of U. S. Four Year Colleges and Universities

White TK, Whitaker P, Gonya T et al (2009) The use of interrupted case studies to enhance critical thinking skills in biology. J Microbiol Biol Educ 10:25-31

Wieman C (2007) A scientific approach. Chang Mag 9-16 